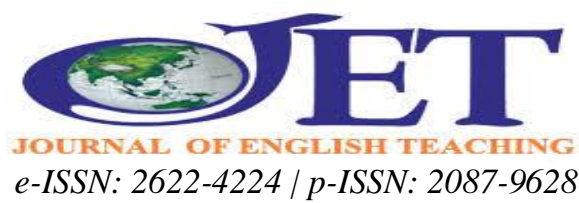

\title{
The Effect of Integrating Mobile Application in Language Learning: An Experimental Study
}

\author{
Trixie Mae Mengorio \\ cmengorio@gmail.com \\ College of Education, Rizal Technological University, Mandaluyong City, Philippines \\ Remart Dumlao \\ dumlaoremart25@gmail.com \\ Faculty of Education, Muban Chombueng Rajabhat University, Rajabhat, Thailand
}

\begin{abstract}
Innovation in Language Teaching Methodology should address the needs and demands of the 21st century learners and the birth of Mobile Aided Language Learning created abundant possibilities for the field of language education. This study investigates the effect of the Mobile Application: Moodle in teaching ESL learners. A quasiexperimental research with 100 respondents in Junior High School at Rizal Technological University-Laboratory High School of the Academic Year 2017-2018. The research data were gathered from the pre-test and post-test results during the betatesting activity and Focus Group Discussion conducted among the experimental set during the 4th grading period. Experimental Set used the Mobile Application: Moodle in their daily classroom discussion and activity tasks. Results shows that there is an increase with the performance of the Experimental Group compared to the Controlled Group test results. Also, the students in the experimental set express positive feedback about the integration of Mobile App in teaching and learning process. The study suggests that with further research and development of the program, it will enhance the possibility of MALL acquisition in teaching ESL
\end{abstract}

Keywords: Mobile Aided Language Learning (MALL), E-learning, M-learning, Mobile Applications

\section{INTRODUCTION}

The fast-pace life style of 21st century requires individuals to use diverse technological devices especially mobile ones in their daily lives. Consequently, educational fields attempt to integrate and use the rapidly-developed technology for enhancing learning process leading to emergence of the notion of mobile-learning. Statista (2018) showed the number of mobile subscriptions worldwide wherein in 2011, the mobile subscription totaled approximately 5.86 billion. On the study of Martin, Pastore and Snider (2012), Developing Mobile Based Instruction, it stated that $75 \%$ or almost 4.5 billion of mobile subscribers came from the developing countries, while the remaining $25 \%$ or estimated of 1.4 billion subscribers came from the developed countries. Clearly, rapid growth of technological devices and informatics technologies and their use in diverse fields motivate and help educators to use them in their instructional designs as learning enhancement tools. 
Over the last three decades second or foreign language (L2) instruction has been one of the major subject areas of education in which technology has played a central role. As more technologies are integrated in L2 instruction, teachers and learners have more opportunities to get globally connected and educated.With recent developments in mobile technology, mobile learning (or m-learning) has also attracted considerable attention in the field of L2 instruction (Kukulska-Hulme, 2009; Saran Seferoğlu, 2010; Saran, Seferoğlu, \& Çağıltay, 2009; Stockwell, 2010). Mobile devices such as netbooks, laptops, iPads, tablets, cellular phones, smartphones, digital cameras, mp3 players, personal digital assistants (PDAs), and e-readers have become very widespread, especially among young people (Franklin, 2011). Thus, L2 instruction via mobile devices has become a research and practice trend in technology-enhanced language learning (Godwin-Jones, 2011). Based on the idea of anywhere and anytime learning, m-learning now provides educators with "a myriad of opportunities to support learning and performance both inside and outside the classroom" (Martin \& Ertzberger, 2013, p. 26).

In modern classroom, mobile apps are just one part of the picture for ESL learners. It effectively help the teachers add a new dimension to their teaching. It also give students a break from the traditional classroom all while still reinforcing the skills they are learning. Total immersion is the best way to learn a language. As technology continued to get more and more popular, classroom attention spans were getting shorter. Godwin-Jones (2011) stated that, "mobile learning (often "m-learning") is in it not new, but new devices with enhanced capabilities have dramatically increased the interest level, including among language educators". This present study investigates the effect of the Mobile Application: Moodle in teaching ESL learners.

\section{Research Questions}

In relation to the background of the problem, the current study was to seek:

1. What is the performance of the students in the control and experimental group using MALL in English language pre-test ad post-test?

2. What are the effects of the Mobile Application to the language learners and teachers in terms of:

2.1 Instructional Materials

2.2 Development of Language Competencies

2.3 Evaluation/Assessment

2.4 Over all learning experience

\section{LITERATURE REVIEW}

The Progress of M-Learning and its Outcome in the World of Language Education Mobile assisted language learning (MALL) first appeared around 2005, when some USA universities began to give their students free mobile devices (Chinnery, 2006). It came to appear more globally around 2009, when the British Council developed mobile applications (apps) for language learning (Hockly, 2013). Major English language teaching (ELT) publishers producing standalone or coursebook-related apps accelerated the development and spread of MALL globally (Dudeney \& Hockly, 2012).

Mobile Assisted Language Learning (MALL) has been widely recognized as providing "portability", "social interactivity", "context sensitivity", "connectivity" and "individuality" for language learners (Miangah \& Nezarat, 2012, p. 311). Over the past decade, a variety of mobile devices have been tried in the field of language education. 
In line with the latest Horizon Report 2012 and 2013 which highlighted the educational potentials of mobile and tablet computing (Johnson et al., 2013), Mobile assisted language learning (MALL) is a burgeoning subdivision of computer assisted language learning in general. As mobile technologies has evolved, so have their advanced applications developed for language education. Mobile device technology has been drastically developed and transformed in an integrated way. In addition to the traditional purpose for oral communication via mobile phones, the current multifunctional mobile technology enable users to access to the Internet ubiquitously for locating and searching information, emailing, reading e-books, and even shopping. The mobility has also enabled learning independent of location and any time even out of classroom (Yang, 2013).

Several scholars introduced and reviewed the use of mobile technology and its applications for language education (Chinnery, 2006; Godwin-Jones, 2011; KukulskaHulme \& Shield, 2007, 2008). Chinnery (2006) comprehensively reviewed empirical research which utilized some of mobile devices including cell phones, PDAs, and iPods. For example, instructors teach short English lessons by sending them to students' emails via mobile phone (Thornton \& Houser, 2005), giving vocabulary instruction via SMS for Italian learners in Australia (Levy \& Kennedy, 2005). Even though Chinnery (2006) reported those above projects were effective for language learning, the underlying concept of those applications of mobile phone seems to be similar to the concept of Web 1.0, in that the interaction was not virtually user-centered or -created. Since the term Web 2.0 was introduced by Tim O'Reilly in 2004, the term, Mobile 2.0, has been used to refer to the mobile technology featuring Web 2.0 (Wang \& Heffernan, 2009). The essential features of Web 2.0 are user-created and collaborative content. Likewise, the new approach to MALL would be co-opted from the feature of Web 2.0.

Kukulska-Hulme and Shield (2007) comprehensively reviewed MALL-related research, emphasizing speaking and listening domains. They overviewed the research in terms of the types of mobile devices including mobile phones, tablet PCs, MP3 players, and so on. More recently, Godwin-Jones (2011) explored the current state of mobile apps for language learning, adding context aware learning apps using GPS, data storage and syncing between "cloud" and mobile device. As Godwin-Jones mentioned, the noticeable development of mobile software are vocabulary learning programs and flashcard software. Besides the apps Godwin-Jones exemplified in his article, such as eStroke, Pleco, Chinese Pod, many other software once operated by Windows or MAC have also increased their exposure by developing iPhone or Android apps. Supermemo, for example, is one of the powerful spaced repetition software (SRS) for vocabulary teaching (Godwin-Jones, 2010), which is more effective than massed learning. Recently, Supermemo has been equipped with sound recognition system, and expanded its usability in multiple platforms including PC, smartphones, and e-learning via website (Yang \& Park, 2012). In addition to the vocabulary learning, because of the increasing distribution and use of smartphones enabling wireless Internet connection, the educational applications of smartphones have been getting diverse and integrated more and more. Therefore the emerging development of the technological properties of language teaching has submerged to the demand of skills in the 21 st century learners. 


\section{The State and the Outcomes of Mobile Aided Language Learning in the Philippines}

In the Philippines, the technological revolution in the field of education has already began, from a traditional materials that used in teaching to suit to the Teacher centered approach of the past curriculums in the country to a more interactive materials such as Computer Assisted Language Learning (CALL) that suit to a Student Centered Approach of the K to 12 Curriculum but it still lacks to reach students in the rural area There is an emerging Mobile Assisted Language Learning Application which includes a portal to help those outside education find courses near them, an app to teach English to out-of-school teenagers through phone calls and another app to help teachers track the progress of students taking such courses. For instance, Ayala Foundation launched a project called Youth Tech in the year 2000, a total of 875 public high schools have been connected to the Internet. Of this number, Youth Tech-GILAS has been responsible for connecting 650 schools, benefiting roughly 780,462 public high school students, concentrating on those in their senior year, and 17,460 teachers. Furthermore, partner schools of the Ayala Foundations' Project Youth Tech observed that there was an increase in students' awareness of technologically related educational tools. The Internet was seen as a useful tool for research and communication. This awareness allowed young Filipinos to learn new computer software and then inspired them to information technology. Another project was the GURO or Grid Utilization on elearning Objects. GURO allowed the idea of e-learning techniques that utilized learning objects (e.g., multimedia contents, learners and teachers curriculum or instructional contents) in the context of Grid computing technology. That program showed useful and helpful approach for enabling the education sector boost in the Philippines. But in the downside, the program still requires an efficient solution to integrate with sharable and collaboration contents of each diverse e- learning platform. Grid Utilization in Learning Objects (GURO) solved the problem in learning resources integration on each varied learning management system. Users or learners could send an e-Learning request through a unified Web interface, create an environment was provided. With regards to the process, GURO program has encountered difficulties such as (1) administering lectures, (2) Unavailability of Lecture Based Teaching Materials and (3) Process of conducting quizzes and other related activities.

As with the fast changing educational diversity we are in nowadays, it is paramount to give ELL's the best learning experiences they can get as schooling period serves as their training ground for the future. Teachers need to ensure that the learners are competent enough with optimum armour that will guarantee their skills can withstand the challenges and demands of 21 st century.

In this paper, the researchers focus on the details of the organization and management of the mobile application system and its impact in the teaching of ESL learning process. This study aims to test the role of m-learning in ESL (English as a Second Language) classrooms. The program will provide instructional materials based on the English Curriculum guide of the school; it includes written evaluation and assessment of each lesson; records of the students will also be available to track the student's performance and may serve as teacher's reference.

\section{METHOD}

The conceptual framework of this study was premised on the conceptualization of the effectiveness and the usage of Mobile Aided Language Learning Portal (MALLP) for 
English Language Learners (ELL)'s and language teachers in learning English as a Second Language.

\section{Participants and Settings}

The population of this study is the tenth grade, English Classes of Rizal Technological University- Laboratory High School. It is composed of two sections out of the four sections of Grade 10 students at the Laboratory High School.

The researchers utilized cluster sampling in the study. Due to the time given to the researchers in conducting the beta-testing, the researchers opted to choose the technique that will represent the entire population of the respondents. The 2 -set of respondents composed of 50 students each, were assigned to their corresponding groups. The table below shows that there are 100 respondents from the entire population of the enrolled Grade 10 students enrolled at Rizal Technological University Laboratory High School Academic Year 2017-2018.

\section{Data Collecting Procedures and Analysis}

The researchers are determined to conduct an experiment to examine the effectiveness of the MALLP in teaching English as a Second Language on English Language Learners (ELL). One of the aims of the researchers is to investigate on how the MALLP helped the ELLs to become more proficient in the English Language compared the usage of the traditional materials in teaching English Language. Also, to investigate the practicability of the MALLP for the language teachers because one of the core objectives of the MALLP are to help language teachers to have an easy-access of acquiring and actual designing their own topics, lesson plans, references notes, assessments, evaluations forms, and test scores for the learners, use as their instructional materials, support for literary development and support their needs in teaching, improve teacher and learners interaction through the MALLP, help the language teachers to change the traditional methods in a way the students learn, updating students' performance on their student profiles within the MALLP which in overview, helps the language teachers to have a more stress-free job to educate the learners.

The study utilized a mixed method design to determine the effectiveness of the MALLP in teaching English Language on English Language Learners (ELL) hence the researchers will be conducted a tryout experiment with fifty respondents particularly the Grade 10 students of the Laboratory High School (LHS) in Mandaluyong City. The experiment will be conducted in a span of 3-4 weeks which includes the orientation, administering the needs assessment to the respondents and the utilization of the traditional and the treatment application to the teaching and learning process in order to track the progress records of the study.

The administration of needs assessment to the respondent is essential to the study in view of the fact that the need assessment served as the researchers' basis on what are the possible requirements of the respondents regarding on the MALLP and also on why the researchers' need to conduct the study on that learning area. After the administration of the needs assessment, the researchers will be distributed pre-examinations to the respondents which served as the foundation of the progress of the respondents before to undergo to the actual tryout experiment.

Subsequently to the pre-examination, the respondents will be undergo to the actual experimentation of the study which the respondents are divided into 2 groups: the control group and the experimental group. The control group will be taught using the 
traditional method while the experimental group will be taught with the use of Mobile Application as a teaching aid. After the experiment, the researchers will be distributed set of post examinations and interview on the experimental group to know the effectiveness of the MALLP which can identify the purposes of using Mobile App to the learning and teaching process.As a whole, the extent to which the MALLP use by the teacher and the learners in the teaching and learning process was observed in this study.

\section{FINDINGS AND DISCUSSION}

RQ 1: What is the performance of the students in the control and experimental group using MALL in English language pre-test ad post-test?

Table 1:

Pre-Test Mean Score Result for the Experimental and Controlled Group

\begin{tabular}{ccc}
\hline \multirow{2}{*}{ Pre-test mean scores } & Experimental group & Controlled group \\
\cline { 2 - 3 } & 27.14 & 24.96 \\
\hline
\end{tabular}

Finding shows that the experimental group obtain high scores with the pre-test examination with 13 students who failed to meet the passing score and the 37 students in the group were able to reach the passing rate. With the statistics provided above, the study found out that before the integration of Mobile Application in the Experimental Group, the group were able to achieved high marks on the exam. The percentage rank of passing rate is at $74 \%$. Therefore, it can be interpreted that before the implementation of the Mobile Application, most of the students were able to pass the examination, with that, it can be depicted that the selected pool of respondents for the experimental group can perform well based on their pre-test results.

Meanwhile, the controlled group acquired lower score compare to the experimental group. With greater number of students who failed in the group, 20 of them were not able to meet the passing score and the 30 were able to get a passing score. While the controlled group landed on $60 \%$ as the percentage passing rate. If we are going to analyze the Table $3 \& 4$ listed above, we can see the big difference among the two in terms of the percentage passing rate and the number of students who passed the test. It only means that the Experimental group performs well compare to the controlled group based on the pre- examination result comparison.

After looking into the Individual performance of the 2 groups, the researchers compared the mean scores test result of the both group. Descriptive statistics shows the result of the Pre-Test Examination of the Experimental and Controlled Group. Based on the numbers shown above,the experimental group garnered 27.14 as the pre-test result mean score while the Controlled group accumulated 24.96. Which implies that the Experimental group gain high score compare to the controlled group before being exposed to the treatment? Notice that there is a difference between the groups' scores of 2.18 . 
Table 2:

Post-Test Mean Score Result for the Experimental and Controlled Group

post-test mean scores

Experimental Group failing scores went down to students. From the 13 students
who failed in pre-test exam, after the treatment application, the number lessens to 2
students. Therefore the 48 students were able to succeed in the passing the post
examination. The percentage rate of the passing score is at $96 \%$. The percentage score
increased from $74 \%$ in pre-test results to $96 \%$ in the post-test scores. In consonance
with Hwang and Wu (2014), that emphasized that language learning is considered as the
most popular application of mobile technology-enhanced learning whilst MALL has
been amply researched on. Evidently, with the results provided by the respondents, it
can be depicted that the integration of MALL has a positive impact towards learning the
subject matter.

The data shows that the post-examination result in the controlled group have 34 students who failed to meet the passing rate. The number of the failing students increase from the pre-test of 20 it went up to 34 in the post-test results. The percentage score of the passing rate dropped down to $16 \%$ compare to the $60 \%$ passing rate from the pretest results.

Looking at the collation between the two groups, it can be seen that after the treatment application, the Experimental Group manifested positive response. From 13 students who failed the pre-examination, the numbers decreased to 2 students who did not pass the post-examination. Meanwhile in the controlled group, the result worsen with the increase of numbers in the failing scores category from 20 to 34 .

Looking over the comparison of the post-test mean scores of the two groups, with 28.86 for experimental and 21.96 for the controlled group, the test results shows the increase in result in post-test examination of the experimental group after the treatment application while there is a decline in numbers in the post test results for the controlled group.

Therefore, it emphasizes the big difference between the performance of the Experimental Group than the Controlled Group. It clearly states that the Experimental Group increases its performance level through the integration of the Mobile Application. The MALL technology implementation increases the education results and students obtain additional competencies in working with information, which, at the same time, increase motivation.

Table 3:

The Performance Scores of Experimental and Controlled Group in thePre-Test and Post-Test Examination

pre-test meanscores post-test meanscores

\begin{tabular}{ccc}
\hline experimental & 27.14 & 28.86 \\
\hline controlled & 24.96 & 21.96 \\
\hline
\end{tabular}

The tabulated data above shows the comparison between the mean scores of the

both groups in the Pre-Test and Post-Test Examination. As the Experimental Group accumulated 27.14 as for the Pre-Test Mean Score and 28.86 for the Post-Test. 
Meanwhile, the Controlled group garnered 24.96 for the Pre-Test Score and the 21.96 for the Post-Test results.

Using mobile ICT in the learning process leads it to a new quality and reflects the modern tendencies in education to the fullest by providing constant access to study resources at any time and in any place and by being a new inventory for the development of a human of informational society, who is capable of mobile-assisted life-long learning (Wagner, 2016). Which was shown based on the Increase with the Scores of the Experimental group after the treatment application.

With the statistics shown above, the experimental group presented an increase with the numbers for the post-test scores after the treatment application. While on the Controlled group, a gap was portrayed by the group with the reduction of scores from Pre-Test to their Post-Test results. It could be depicted that the usage of the mobile application in experimental group gave the progress to the learning performance of the whole class compared to the reductions of scores in the controlled group.

\section{RQ 2: The effects of the Mobile Application to the language learners and teachers In Terms of Instructional Materials Innovative}

According to the statement provided by the Student-Teacher X and Y, they used different instructional materials along with different methods of teaching the ELLs. Based on the data gathered by the researchers, Student-Teacher X used three elements in every class session: "traditional, the use of ICT, and board work or paper-and-pencil work".

Student-Teacher X emphasized the traditional and modern instructional materials and methods of teaching. As mentioned the three elements above, these traditional materials include the use of visual aids such as cartolina or manila paper, cartolina strips, flashcards or pictures and etc.; the used of book is highly used in traditional teaching. Other type of instructional materials under the traditional method is the board work or the paper-and-pencil work. The teachers asked the students to do a particular activity on board or on paper work. This method is useful to enhance the skills on the learners in a particular type of competencies such as writing and grammar. Furthermore, Student-Teacher X also used the ICT or other alternative learning resources such as computers, gadgets, e-learning and etc. and refer as the modern method of teaching. With the help of those technologies, the teachers could teach the learners innovatively and surely enhance the students learning competencies.

On the other hand, Student-Teacher $\mathrm{Y}$ used the "communicative and direct method" in the class discussion: it means that the target language was mostly used rather than the native language or the mother tongue. Based on the interpretation of the researchers, Student-Teacher Y trying to tell is that, the use of the target language communicatively and directly would eventually help the language learners to learn the Subject. However, all these methods, as given by Student-Teacher X and Y, could be used even the teacher or the students used the mobile app in ESL classroom.

The researchers strongly believed that all the methods provided were appropriate even if the students used the Mobile App as a tool of learning the Subject. The mobile app was the product of innovation whereas ICT refers to the modern method of teaching and some the activities included on the mobile app could be done in traditional way particularly the group or individual activities. 
The researchers also think that the availability of the resources such as mobile phones and data or internet connections would help the students prior to this problem, since the content of the app can be updated with the help of internet connection.

\section{In Terms of Development of Language Competencies Not all Language Competencies were Met}

Language competencies are significant to the development of the learners, it could assist the learners to be a more globalized individual and serve as a building blocks to their foundation of their knowledge which is one of the salient features of a Mobile Assisted Language Learning is to ensure the attainment of the language competencies. Scholars have, however, debated on the effectiveness of MALL, showing slight distrust towards these technologies when compared to the traditional teaching system or advocating that MALL is changing the landscape of former learning processes, making these spontaneous, informal, personalized and ubiquitous (Miangah \& Nezarat, 2012).

Student-Teacher X claimed that some competencies were met within the duration of the beta-testing by using the Mobile App as he stated that:

"Grammatical/Linguistic Competence, Sociolinguistic Competence, Discourse Competence and Strategic Competence were at some point met."

However, due to brief time of period that was given to the beta-testing of the Mobile App, Student-Teacher X claimed that was the reason why not all of the competencies were attained by the learners, as he stated that:

"Given a very short period of time plus the changes in the school calendar of RTU-LHS I don't think that "all" target competencies were met."

\section{In Terms of Evaluation/Assessment}

\section{Decrease In Paper And Pencil Assessment}

During the testing period, the student teachers observed a lot of changes in terms of teaching strategies, the use of Instructional materials, crafting of the evaluations and other areas in language teaching. As what Student-Teacher X stated during the FGD Session, "the decrease in paper and pencil assessments" is what he observed the most. The learners actually used the app in class discussion, whether it's a drill, a motivation, an activity, and even the recordings of the students were included in the app. That's why paper-and-pencil works were decrease since the students, and the teachers, would eventually rely on the app since it had all the teachers need.

The lessons and activities could be done through the student's mobile phone. Student-Teacher $\mathrm{X}$ added that the use of Mobile App was "more convenient way of recording the learner's scores" since one of the feature of the application is to record all the activities of the students as long as they finish it.

In addition, the Mobile App also provided a convenience to their teaching duties as she stated that: "The use of paper-and-pencil had lessen."which AVATUS Mobile App clearly brought the idea of Miangah and Nezarat to life which (Miangah \& Nezarat, 2012) stated that a Mobile Assisted Language Learning can serve as a medium of instruction and portability to the teachers. 


\section{In Terms of Overall learning experience \\ Helpful}

The students found the Mobile App in learning the English Subject as "helpful", since all the resources or learning materials are included as long as the app is installed on their phones. As stated by Student 1:

"very helpful because the mobile app makes it very easy to understand the subject more."

The app has its own feature of lessons and activities. It makes the learning process helpful because all the learning materials are included such as the literary pieces, the grammar points, and the activities which the objective is to reach the target language competencies. In addition, Student 2 assert that:

"maari na kaming mag-advanced reading sa lessons na ididiscuss at sa mga activities para pagdating sa school prepared na lahat at magiging madali ang discussion". (We can do advance reading in our lessons and list of activities so that when we get to school we are prepared and the discussion will be easy.)

The researchers believe that it makes the learning the English Subject helpful because all the lessons, including the activities are entailed. The students can use the app anytime, anywhere. It helped them to do the advance study that would eventually help them on the actual class discussion. Student 3 added that:

"I find it more helpful at tsaka mas medaling maka-access."

(I find it more helpful and can be access easily)

The accessibility of the app made it more helpful because anyone can use it as long as the app is installed.

\section{Easy}

Furthermore, the students assert that they find the mobile app "easy" in learning the English Subject. Student 8 from the experimental class stated that:

"Learning my English Subject using the Mobile App become easy because it is installed in our cellphones... it has the summary and it is more understandable."

The researchers made the mobile app as interesting as it is to increase the interests of the students in learning the subject. They made sure that the mobile app is userfriendly; it is easy to access and easy to use. The students just need to download the app, and that's it. Learners can use the app as easy as that.

Boon and bane are part of using technology, especially if it is new to the users. Technology users can't deny the fact that there are still some disadvantages of using it. In today's generation, technology is a necessity in human's daily life. In the field of education, there are many instances that the use of mobile phone during the class discussion has a positive and negative effect in terms of learning a particular lesson.

\section{Enjoyable}

On the interview conducted by the researchers, the students found the use of mobile phone during the class discussion as "enjoyable" for positive effect, and "distraction" for negative effect. Student 2 professed that 
"More people will be active in the class because they are using it in a daily basis."

With the help of some visual effects, the researchers believe that it would add an extra effort to the interest of the learners in learning ESL. What fascinated the researchers most is when Student 5 stated this:

"Mas nag-eenjoy ang mga students sa bagong style ng pagtuturo na gamit ang app."

(the student enjoyed more with the new style in teaching using the app)

The student thinks beyond those teaching style that the mobile app which the researchers used on their study, is a new style or trend in teaching. In addition to this, Student 4 recommended:

"It's easier to use if paired with dictionary apps or thesaurus apps if students have a hard time of understanding words."

However, there were still some implications of using it. The students that the researchers interviewed conclude that, some of the classmates did not totally participate prior to the testing of the mobile app. Some students were pretending of using mobile phone as a tool in learning but they actually visited some mobile applications rather than the Mobile Appas what the researchers quoted from Student 6 statement: "people tend to use other apps and say they are using the mobile app... some of my classmates where using Facebook and I caught them video chatting".

It was supported by Student 2 stated that "Maaring samantalahin ng mga bata ang paggamit nito sa paglalaro ng games sa cp at pag-oopen ng social media sites, maaring makaka-destruct ito sa learning ng mga students."(Students might abuse the usage of the app by playing games and browsing social media sites on their phones, it can also distruct their attention in learning)

According to Student 1, the use of mobile app encouraged him because "it has more potential to make students understand more," which means that though the student used a mobile phone but if that application they're going to use is informative and reliable, the students would learn more. Student 3 added that "It encourage me because it notify me every day and also the activities are entertaining."

It only implied that the Mobile App attract the interest of the learners wherein it made the learners entertained as well as learned the subject. The researchers believe that the everyday notification from the Mobile App would surely help the students to be on track and remember what they need to do or to pass prior to their requirements.

Furthermore, Student 5 assert that with the use of Mobile App,"mas napadali nito ang learning naming sa English, before the class we have the idea na kung tungkol saan ang ilelesson at yung mga activities naging less hustle"(it made learning English easier, before the class we have the idea about the topics as well as the activities ). It only means that, not only the lessons, but also the activities which captured the interests of the students in learning ESL.

It became as an "alternative learning device/s" as quoted Student 3. This technology refers as a tool in teaching, specifically with the use of computers and gadgets.

With the regards to the use of mobile app-in learning ESL, the students assert that they had a "meaningful learning experience" in their English Subject. Student 6 stated 
that, "yes, because with the help of technology, you can have a meaningful and fun experience learning English".

Quoting the statement of "with the use of technology", the researchers believe that with the use of MALL (Mobile-Aided Language Learning), ELLs would be influenced and eventually increase the students' interest to learn the subject. In addition to that, Student 5 added: "it is a different experience because the lesson is at your phone that you have access every day".

\section{CONCLUSION AND SUGGESTIONS}

There is no such perfect methodology in applying a mobile app as a tool in teaching English; it does not literally means that it is not appropriate in class discussion. Through this, the researchers can eventually think other possible solutions on how to deal with this that eventually fall into recommendations. For the future researchers, this may help them in conducting their study related to the use of mobile app in teaching ESL.

In a simple sense, technology did not only change the traditional method of teaching, but also with the innovation of the materials used in learning ESL. At the means of testing period, the researchers found out that some students had a fun experience in using the app, while some students at first said that it's quite hard to deal with. Overall, students experienced a fun and enjoyable English class, but still had some struggles in data connections.

\section{REFERENCES}

Ayala Foundation Celebrates 40 Years Of Breaking Barriers. (2002). Retrievedfromhttp://www.ayala.com.ph/press-room/press-releases/ayalafoundation-celebrates-40-years-breaking-barriers

Chinnery, G. M. (2006). Going to the MALL: Mobile assistedlanguagelearning. Language Learning \& Technology, 10(1), 9-16.

Dudeney, G., \& Hockly, N. (2012). ICT in ELT: How didwegethere and where are wegoing? ELT Journal, 66 (4), 533-542.

Franklin, T. (2011). Mobile learning: at the tipping point. Turkish Online Journal of Educational Technology, 10(4), 261-275.

Godwin-Jones, R. (2011). Emerging technologies mobile apps for language learning. Language Learning \&Technology, 15(2), 2-11.

GURO (Grid Utilization in E-learning Objects) (2018). Utilization of gridcomputing in the Philippines: a cost and benefit analysis and focus on e-learning capability

Hockly, N. (2013). Mobile learning. ELT Journal, 67(1), 80-84.

Johnson, L., Adams Becker, S., Cummins, M., Estrada, V., Freeman, A., \& Ludgate, H. (2013). NMC Horizon Report: 2013 Higher Education Edition.

Kukulska-Hulme, A. (2009). Will mobile learning change language learning? ReCALL, 21 (2), 157-165.

Kukulska-Hulme, A. \& Shield, L. (2008). An overview of mobile assistedlanguagelearning: from content delivery to supported collaboration and interaction. ReCALL, 20 (3), 271-289

Levy, M., \& Kennedy, C. (2005). Learning Italian via mobile SMS. In A. KukulskaHulme, \& J. Traxler (Eds.), Mobile learning: A handbook for educators and trainers (pp. 76-83). London: Taylor and Francis. 
Martin, F., \& Ertzberger, J. (2013). Here and now mobile learning: An experimentalstudy on the use of mobile technology. Computers \& Education, 68, 76-85

Miangah, T. M., \& Nezarat, A. (2012). Mobile-assistedlanguagelearning. International Journal of Distributed and ParallelSystems, 3(1), 309.

Saran, M., and Seferoğlu, G. (2010). Supporting foreign language vocabulary learning through multimedia messages via mobile phones. Hacettepe University Journal of Education, 38, 252-266.

Stockwell, G. (2010). Using mobile phones for vocabulary activities: Examining the effect of the platform. Language Learning \&Technology, 14(2), 95-110.

Saran, M., Seferoğlu, G., \& Çağıltay, K. (2009). Mobile assistedlanguagelearning: English pronunciationatlearners' fingertips. Eurasian Journal of Educational Research, 34, 97-114.

Thornton, P., \& Houser, C. (2005). Using mobile phones in English education in Japan. Journal of Computer Assisted Learning, 21, 217-228

Wagner, M. (2016). Perspectives of Introduction of the Mobile-AssistedLanguage Learning (Mall) Technology, International Journal of Environmental \& Science Education, 11(15), 8562-8571.

Wang, S., \& Heffernan, N. (2009). Mobile 2.0 and Mobile Language Learning. In M. Thomas (Ed.), Handbook of Research on Web 2.0 and Second Language Learning (pp. 472-490): IGI Global.

Yang, B., Zhou, S., and Ju, W. (2013). Learning English Speakingthrough MobileBasedRole-Plays: The Exploration of a Mobile English Language Learning App called Engage EF Labs, Education First. The EUROCALL Review, 21 (2).

Yang, J. (2013). Mobile AssistedLanguage Learning: Review of the Recent Applications of Emerging Mobile Technologies. English Language Teaching, 6. 